American Journal of

Health, Medicine and Nursing Practice (AJHMN)

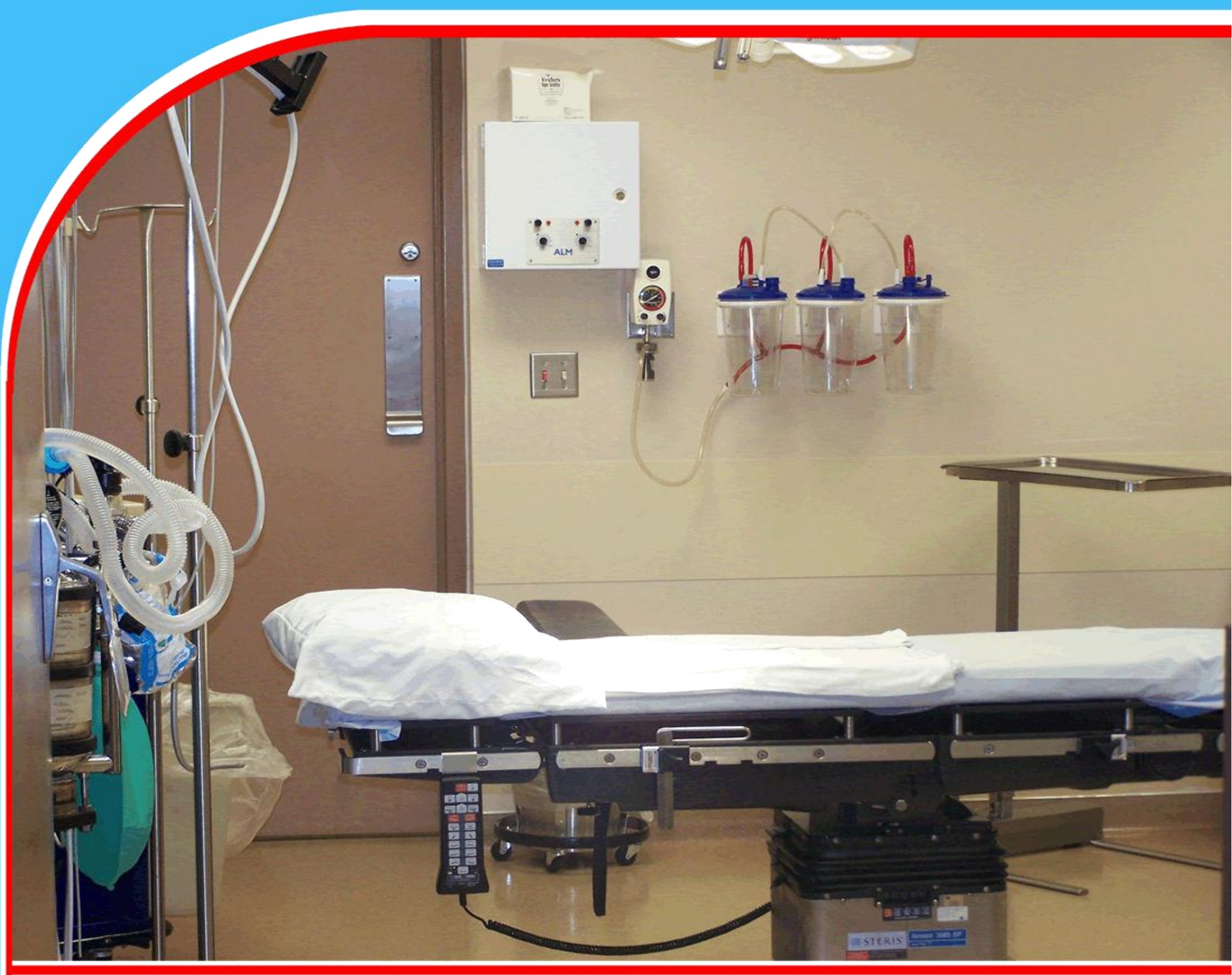

SONOGRAPHIC INCIDENCE AND EXTENT OF LOWER LIMB DEEP VENOUS THROMBOSIS IN HOSPTILISED PATEINTS OF TERTIARY CARE HOSPITAL

Muhammad Saleem

Mahrukh Samuel

Asifullah

Faizan Shabbir

Namra Zamir

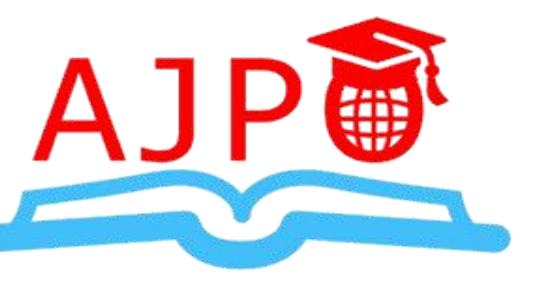




\title{
SONOGRAPHIC INCIDENCE AND EXTENT OF LOWER LIMB DEEP VENOUS THROMBOSIS IN HOSPTILISED PATEINTS OF TERTIARY CARE HOSPITAL
}

\author{
"Muhammad Saleem, Mahrukh Samuel, Asifullah, Faizan Shabbir, Namra Zamir \\ Undergraduate students: Medical Imaging Doctors \\ University Of Lahore \\ Supervisor: Iqra Manzoor \\ Co-supervisor: Dr. Ilyas Sadiq \\ Data analysis: Mehreen Fatima, Yousaf Gillani \\ *Corresponding Author's E-mail: saleemazeem1122@gmail.com
}

\begin{abstract}
Purpose: The aim of our study was to determine the incidence and extent of deep venous thrombosis in hospitalized patient of tertiary care hospital.

Methodology: This was observational cross sectional study. The data of patients had been collected from Jinnah hospital Lahore, Pakistan. After taking informed consent, data was collected through the Doppler ultrasound which was performed for lower limb in symptomatic patients. Equipment used was TOSHIBA Xario (200) with linear probe frequency ranging from 7-10 MHz. The data analysis was performed with the help of SPSS version 24.

Findings: Total 124 patients were included in this study in which the mean age of the patient was $45.38 \pm 16.846$ with a range of $14-90$ years. The Mean weight of patients was $=70.31 \pm 9.285$ with the range $48-90 \mathrm{~kg}$. The females were 56 and males were 68 in number included in this study. Out of 124 patients, right leg DVT present in 44(35.5\%), and left leg DVT present in 74(59.7\%), and bilateral DVT present in $6(4.8 \%)$ of patients.

Unique contribution to theory, practice and policy: It was concluded that age plays a significant role in the development of DVT. Patients with acute DVT have hypoechoic thrombus while the chronic DVT have hyperechoic echogenicity. DVT was most commonly seen in the left leg in comparison with right leg. Ultrasound is the best modality in the detection of DVT.
\end{abstract}

Key words: Ultrasonography, Deep Venous Thrombosis, Doppler ultrasonography, Venous Thromboembolism 


\section{INTRODUCTION}

Deep venous thrombosis (DVT) is a typical disease with potentially serious outcomes, like pulmonary embolism ${ }^{1}$. The incidence of DVT in the overall population is somewhere in the range of 1.6 and 1.8 per 1000 for each year ${ }^{2}$. Due to the body's own natural defense system against clotting of blood such as thrombomodulin, anti-thrombin III, protein C, protein S, smooth walls of the vessels and regular smooth flow of blood through vessels blood inside the vessels usually does not clot normally. Virchow in 1920s explained that blood clots inside the vessels results in the thrombus formation due to three major factors which are known as the Virchow's Triad, for example changes in the blood vessel wall endothelium, changes in the blood flow pattern, and changes in the composition of the blood chemical properties. Any kind of change in the defense mechanism leads to deep venous thrombosis ${ }^{3}$. A blood clot develop inside the blood vessel is a clump of blood that is in a gelatinous thick or solid state ${ }^{4}$. Deep vein thrombosis could be symptomatic such as leg pain or swelling, but also can occur with no symptoms ${ }^{5}$.

Deep Vein Thrombosis is a serious and potentially fatal disease that can complicate the course of hospitalized patients ${ }^{6}$. DVTs that occurs with symptoms are less frequent, composed of only $3.4 \%$ of the overall population ${ }^{7}$. The incidence rate of venous thrombosis related to pregnancy is approximately 1 for each 1,000 of pregnancies ${ }^{8}$. Rate of mortality among elderly patients, per year because of pulmonary thromboembolism and deep venous thrombosis are $39 \%$ and $21 \%$ respectively. In that study, vascular doppler ultrasonography was performed as a dependable technique for diagnosing of deep venous thrombosis in perspective on the way of its high specificity and sensitivity in the diagnosis of DVT therefore it has practically replaced venography, and also has easy availability and is cheap modality therefore has good cost-benefit profile ${ }^{9}$. After a symptomatic DVT the recurrent rate is high because of previous history of DVT ${ }^{10}$. One of the most serious life-threatening complication due to DVT is Pulmonary Embolism(PE), a severe PE can cause failure of lungs and hence lead to death ${ }^{11,12}$.

Ultrasound (US) is a simple, appropriate, basic and noninvasive imaging modality of choice in diagnosing DVT. Direct venous compression ultrasound (VCU) is reliable and the most sensitive instrument in the diagnosis of DVT by slightly compressing the vein with ultrasound probe and color Doppler US can show further explained data from the structure of the veins and its opening ${ }^{13}$. Ultrasound has to a great extent replaced the conventional analytic methodology contrast venography ${ }^{14}$. DVT can be analyzed by direct imagining of clot and absence of complete compression of veins. Adjunct outcomes include shows that with augmentation there is absence of variation in the spectral Doppler wave pattern or color flow and also lack of phasic deviation in flow pattern in Doppler with respiration ${ }^{15}$.

The aim of this study was because of the true incidence and extent of DVT is unknown there was high rate of missed diagnosis. Only few studies are published literature most of which were done only on surgical patients. On the incidence of DVT there is a lack of sufficient studies. On the risk of DVT among hospitalized medically-ill patients there are little published data available. Hence, we sought to study the profile of the sonographic incidence of DVT among medically-ill patients treated at a tertiary care hospital. 


\section{MATERIAL AND METHODS}

This was a cross-sectional study on sonographic incidence and extent of lower limb deep venous thrombosis in hospitalized patients of tertiary care hospital. A total of 124 individuals were enrolled in this study including male and female. The study was carried out in Radiology department of Jinnah hospital Lahore. The duration of the study was from July 2019 to November 2019. Convenient sampling technique was used. The individuals of all ages, male and female with suspected DVT were included in the study. The individuals with any other abnormality were excluded from the study. Toshiba (Xario 200) with curved-linear transducer frequency range 7$10 \mathrm{MHz}$ was used for this study. All the patients were scanned under the American Institute of Ultrasound in Medicine vascular protocols which are routinely observed in this department. All information and collected data were kept confidential. Data were collected through data collection sheets and was tabulated and analyzed using Statistical Package for the Social Sciences (SPSS) version 24 (SPSS 24, IBM, Armonk, NY, United States of America), Microsoft Excel.

Patients were scanned mostly in supine position, but erect and seated in a reclined position were also used to allow access to the groin. Focused was to obtained good quality images through low PRF (velocity) color / power / Doppler settings with low wall filter, frequencies were adjusted according to patient's body habitus. Scan were begin with the patient supine with slightly external rotation of leg. Gray scale and color Doppler images of common femoral vein at Sapheno-femoral junction in transverse were obtained in the groin. Color Doppler, spectral Doppler and compression techniques were used to exclude DVT longitudinal images with color filling and pulse Doppler were also carried out for the confirmation of patency. Pulse wave Doppler was performed while during the Valsalva maneuver was performed. Popliteal vein were scanned with the transverse probe position at the knee crease in the popliteal fossa. For obtaining good quality images, difficult patients were examined in erect and sitting positions. Scan was continued distally, tried to visualize the calf veins in sagittal plane with the help of color Doppler for veins patency. Findings were documented, images including, color and pulsed Doppler were printed/ copied/ archived for data analysis.

\section{RESULTS}

Total 124 patients were included in this study, females were 56(45.2\%) and males were $68(54.8 \%)$ enrolled in this study. Mean of the age was $45.37 \pm 16.84$ with age range between 14-90 years. The Mean of the weight was $=70.31 \pm 9.285$ with the range of 48-90 kgs. Results shows how many number of veins involved. Patients which involved only one vein were $n=29(23.4 \%)$, patients with two veins involved were $n=63(50.8 \%)$, patients with three veins involved were $n=32(25.8 \%)$. Results shows that out of 124 patients, right leg DVT present in 44(35.5\%), and left leg DVT present in 74(59.7\%), and bilateral DVT present in $6(4.8 \%)$ of patients. 
Table 1: Gender

\begin{tabular}{lrr}
\hline & Frequency & Percent \\
\hline Female & 56 & 45.2 \\
Male & 68 & 54.8 \\
Total & 124 & \\
\hline
\end{tabular}

Table: 1 shows the frequency and percentages of gender

Findings shows that out of 124 patients, frequency of gender which is consist of females are $56(45.2 \%)$ and males are 68(54.8\%).

Table: 2 Age of patients

Std.

\begin{tabular}{lrrrrr} 
& $\mathrm{N}$ & Minimum Maximum & Mean & Deviation \\
\hline Age & 124 & 14.00 & 90.00 & 45.3790 & 16.84583 \\
\hline
\end{tabular}

Results of this study shows that the minimum age of the patient was 14 years and maximum was 90 years.

Table: 3 Weight of patients

\begin{tabular}{lcrrlr}
\hline & & & & & \multicolumn{1}{c}{ Std. } \\
& $\mathrm{N}$ & Minimum Maximum & Mean & Deviation \\
\hline Weight & 124 & 48.00 & 90.00 & 70.3065 & 9.28516 \\
\hline
\end{tabular}

Table: 4 Number of veins involved

\begin{tabular}{llrr}
\hline & \multicolumn{2}{c}{ Frequency } & Percent \\
\hline (single) & 1 & 29 & 23.4 \\
(double) & 2 & 63 & 50.8 \\
(triple) & 3 & 32 & 25.8 \\
& Total & 124 & 100.0 \\
\hline
\end{tabular}




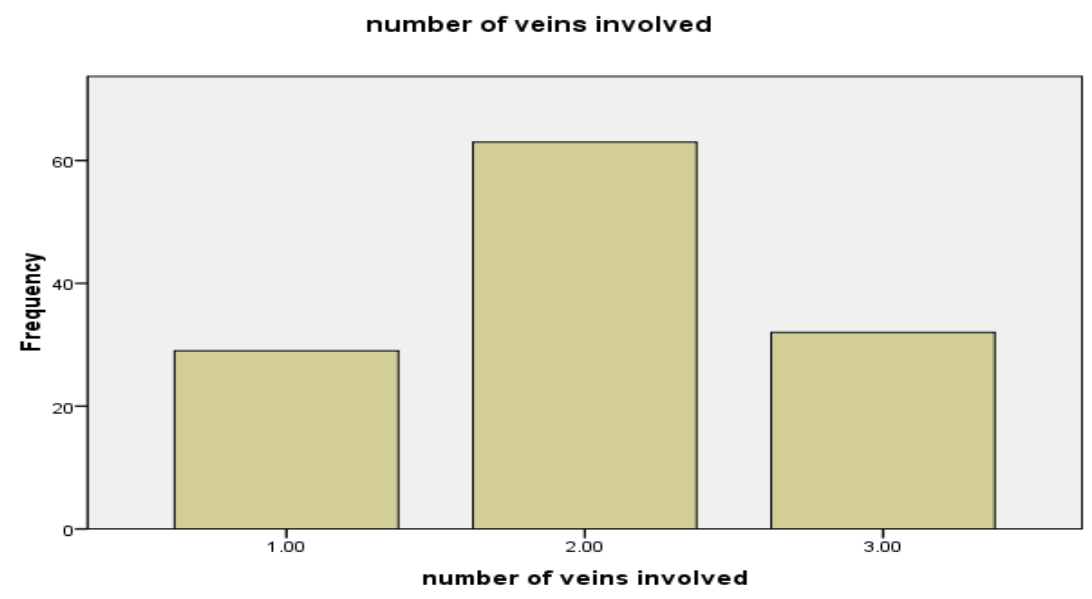

Figure: 1 Bar chart shows the number of veins involved

Bar chart shows how many number of veins involved. Out of 124 patients number of the patients which involve only one vein are $n=29(23.4 \%)$, patients with two veins involved are $n=63(50.8 \%)$, patients with three veins involved are $\mathrm{n}=32(25.8 \%)$.

Table: 9 Echogenicity of thrombus

\begin{tabular}{lrr}
\hline & Frequency & \multicolumn{2}{c}{ Percent } \\
\hline Hyperechoic & 52 & 41.9 \\
Hypoechoic & 72 & 58.1 \\
Total & 124 & 100.0 \\
\hline
\end{tabular}

Table: 5 Final Diagnosis

\begin{tabular}{lrrr}
\hline & Frequency & \multicolumn{2}{c}{ Percent } \\
\hline Bilateral Leg & 6 & 4.8 \\
Left Leg DVT & 74 & 59.7 \\
Right Leg & 44 & 35.5 \\
DVT & & $100.0 \%$ \\
Total & 124 & \\
\hline
\end{tabular}




\section{Final Diagnosis}

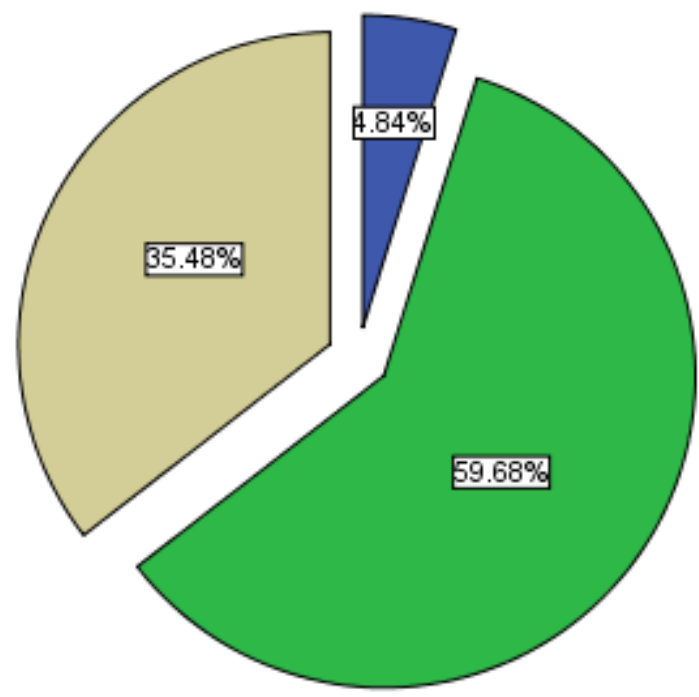

Figure 2 shows the final diagnosis of disease

It shows that out of 124 patients, right leg DVT present in 44(35.5\%), and left leg DVT present in $74(59.7 \%)$, and bilateral DVT present in $6(4.8 \%)$ of patients.

Table: 6 Gender * Diagnosis Cross tabulation

\begin{tabular}{|c|c|c|c|c|c|c|}
\hline & & & \multicolumn{3}{|c|}{ Diagnosis } & \multirow{2}{*}{ Total } \\
\hline & & & Bilateral Leo & Left L eo DVT & $\begin{array}{l}\text { Right Leg } \\
\text { DVT }\end{array}$ & \\
\hline \multirow[t]{4}{*}{ Gender } & Female & Count & 0 & 33 & 23 & 56 \\
\hline & & $\%$ within Gender & $.0 \%$ & $58.9 \%$ & $41.1 \%$ & $100.0 \%$ \\
\hline & Male & Count & 6 & 41 & 21 & 68 \\
\hline & & $\%$ within Gender & $8.8 \%$ & $60.3 \%$ & $30.9 \%$ & $100.0 \%$ \\
\hline \multirow[t]{2}{*}{ Total } & & Count & 6 & 74 & 44 & 124 \\
\hline & & $\%$ within Gender & $4.8 \%$ & $59.7 \%$ & $35.5 \%$ & $100.0 \%$ \\
\hline
\end{tabular}

Table 6 shows that among 124 patients, females with left leg DVT are 33(58.9\%), and with right leg DVT are 23(41.1\%), no female with bilateral DVT. Males with left leg DVT are n=41(60.3\%), and males with right leg DVT are $\mathrm{n}=21(30.9 \%)$, and with bilateral DVT are $\mathrm{n}=6(8.8 \%)$. Overall out of 124 patients left leg is involved in $n=74(59.7 \%)$, right leg involved in $n=44(35.5 \%)$, and bilateral DVT diagnosed in $\mathrm{n}=6(4.8 \%)$, of patients. 
American Journal of Health, Medicine and Nursing Practice

ISSN 2520-4017 (Online)

Vol.5, Issue 1 No.1, pp $1-11,2020$

Www.ajpojournals.org

Table: 7 Gender * Echogenicity Cross tabulation

\begin{tabular}{|c|c|c|c|c|c|}
\hline & \multicolumn{4}{|c|}{ Echogenicity } \\
\hline & & & Hyperechoi & Hypoechoic & Total \\
\hline \multirow[t]{4}{*}{ Gender } & Female & Count & 20 & 36 & 56 \\
\hline & & $\begin{array}{c}\% \text { within } \\
\text { Gender }\end{array}$ & $35.7 \%$ & $64.3 \%$ & $100.0 \%$ \\
\hline & Male & Count & 32 & 36 & 68 \\
\hline & & $\begin{array}{c}\% \text { within } \\
\text { Gender }\end{array}$ & $47.1 \%$ & $52.9 \%$ & $100.0 \%$ \\
\hline \multirow{2}{*}{\multicolumn{2}{|c|}{ Total }} & Count & 52 & 72 & 124 \\
\hline & & $\begin{array}{c}\% \text { within } \\
\text { Gender }\end{array}$ & $41.9 \%$ & $58.1 \%$ & $100.0 \%$ \\
\hline
\end{tabular}

Table 7 shows that among 124 patients, females with chronic DVT have Hyperechoic thrombus and are $n=20(35.7 \%)$, with acute DVT have Hypoechoic thrombus and are $n=36(64.3 \%)$, in numbers. Males with chronic DVT have Hyperechoic thrombus and are $n=32(47.1 \%)$, and with acute DVT have Hypoechoic thrombus and are $n=36(52.9 \%)$.

\section{DISCUSSION}

Deep venous thrombosis is a typical disease and with possibly serious complications, like as pulmonary embolism. The incidence rate of DVT throughout population is in between the range of 1.6 and 1.8 per 1000 for every year. Deep Vein Thrombosis (DVT) is a serious and potentially fatal disease that can complicate the course of hospitalized patients. . Accurate prevalence and the frequency of venous thrombosis isn't known. This study was conducted to find the sonographic incidence and extent of lower limb deep venous thrombosis in hospitalized patients of tertiary care hospital. That has been observed from the patients came to hospital with the symptoms of the DVT. The results of this study are compared to a study conducted by Zamir Q et al. shows 120 patients of total enrolled to their study in which similar age group peoples are observed and included to their study. Studies have also shown that the incidence of DVT increases exponentially with aging, predominantly $>40$. It is not clear if the reasons for these are changes in the clotting mechanism or the presence of thrombogenic morbidities. Out of the 120 patients of total, 49(41\%) were females and $71(59 \%)$ were males. Patients were $>40$ years of age of the total 120 were $68(57 \%)$. They concluded that right leg involved in 34(28\%), both legs in 33(28\%) and left leg was involved in $53(44 \%)^{3}$. The results our study are compared with another research conducted by Goldstein LN et al. in 2018 shows that deep venous thrombosis was diagnosed in 74 of the patients; 56 (75.7\%) with distil lower limb DVT and 13 (17.6\%) with inaccessible pulmonary embolism. The range of age was between 19-90, and hence, 40 years median age of the patients with deep venous thrombosis years. The patients were five $(6.8 \%)$ who had a recurrent DVT with pulmonary embolism $^{16}$.

Results of this research are similar to another research conducted by Rubin JM et al. which shows that 54 patients joined in their research. There were 28 patients with chronic DVT, mean age was 
59.4 years, with a range of 27 to 89 years and 26 patients with acute DVT. Patients included were; 15 were female and 11 were male of the patients with acute DVT. The constant gathering of all these patients was contained ${ }^{17}$.

Results of our study also compared with another research that was directed by Zhao L et al. they investigated 25 sequential emergency clinic in-patients (18 male, 7 female; age between ranges of 37-87 years). The middle echogenicity of thrombus at standard communicated as the grayscale middle value was 59. There was a pattern for thrombus association (estimated as echogenicity) to augmentation with time. The thrombus with acute DVT are hypoechoic and with time echogenicity of thrombus increases in chronic DVT ${ }^{18}$. Results this current research also compared to another study was also performed in 2017 that reveals that the patterns of DVT were noted to be single or multiple levels. And it was either unilateral or bilateral. The functional efficiency of each study was developed from a relative scale of clinical impact based on risk of PE identified in the research $^{19}$.

This above study also compared to a previous study reveals that the site and extent of thrombus seen and veins involved subdivided into segments. The mean age was 58 with age range 18-98 years. Left sided DVT was most common and involved 57\%. In this cohort of 1,338 only 370 patients ( $28 \%$ of total cohort) involved one vein segment. In a group of 506 patients (38\% of total cohort) two veins were involved in DVT, whereas remaining of the patients involved more than two veins presented with $\mathrm{DVT}^{20}$.

In our study it is revealed that male are more involved in DVT than females. It was identified that on gray scale the acute DVT was hypoechoic and the chronic DVT was visualized as hyperechoic thrombus. Most of the patients were involved with left leg DVT then right leg and few presented with bilateral DVT.

\section{CONCLUSIONS}

It was concluded that age plays a significant role in the development of DVT. Patients with acute DVT have hypoechoic thrombus while the chronic DVT have hyperechoic echogenicity. DVT was most commonly seen in the left leg in comparison with right leg. Ultrasound is the best modality in the detection of DVT.

\section{RECOMMENDATIONS}

The study recommended that if ultrasound is not reliable in some situations, there is another way to diagnose DVT, which should be through Venography, which is also a beneficial method but is minimally invasive. CT angiography may also be performed for the diagnosis of DVT when the diagnosis with the ultrasound is not precise.

\section{LIMITATIONS:}

- Current study had some limitations. The sample size was limited and the results cannot be generalized on a larger sample.

- Most of the participants in study were males. 
American Journal of Health, Medicine and Nursing Practice

ISSN 2520-4017 (Online)

Vol.5, Issue 1 No.1, pp $1-11,2020$

www.ajpojournals.org

\section{REFERENCES}

1. Kassaï B, Boissel J-P, Cucherat M, Sonie S, Shah NR, Leizorovicz AJT, et al. A systematic review of the accuracy of ultrasound in the diagnosis of deep venous thrombosis in asymptomatic patients. 2004;91(04):655-66.

2. Adam A, Yousef M, Wahab BA, Abukonna A, Mahmoud MZJPjor. Duplex ultrasound for evaluation of deep venous blood flow in fractured lower extremities. 2018;83:e47.

3. Zamir Q, Shah AR, Bhatti AM, Wajid AAJJTJotPMA. Frequency of proven risk factors for deep vein thrombosis in clinical patients: Results of a study on patients being treated at a tertiary care hospital in Rawalpindi, Pakistan. 2015;65(1):110-2.

4. Scandroglio AM, Kaufmann F, Pieri M, Kretzschmar A, Müller M, Pergantis P, et al. Diagnosis and treatment algorithm for blood flow obstructions in patients with left ventricular assist device. 2016;67(23):2758-68.

5. Cho E-S, Chung J-J, Kim S, Kim JH, Yu J-S, Yoon C-SJKjor. CT venography for deep vein thrombosis using a low tube voltage $(100 \mathrm{kVp})$ setting could increase venous enhancement and reduce the amount of administered iodine. 2013;14(2):183-93.

6. Sial J. DEEP VEIN THROMBOSIS: PRESENTATION AND CLINICAL RISK FACTORS AMONG THE PATIENTS AT A TERTIARY CARE HOSPITAL OF NORTHERN SINDH. Pakistan Journal of Cardiology 2011;21:17.

7. Geerts WH, Heit JA, Clagett GP, Pineo GF, Colwell CW, Anderson FA, et al. Prevention of venous thromboembolism. 2001;119(1):132S-75S.

8. Jacobsen AF, Skjeldestad FE, Sandset PMJAjoo, gynecology. Incidence and risk patterns of venous thromboembolism in pregnancy and puerperium - a register-based case-control study. 2008;198(2):233. e1-. e7.

9. Okuhara A, Navarro TP, Procópio RJ, Leite JOMd. Incidence of deep venous thrombosis and stratification of risk groups in a university hospital vascular surgery unit. Jornal Vascular Brasileiro 2015;14(2):139-44.

10. Hansson P-O, Sörbo J, Eriksson HJAoim. Recurrent venous thromboembolism after deep vein thrombosis: incidence and risk factors. 2000;160(6):769-74.

11. Kuo WT, Sista AK, Faintuch S, Dariushnia SR, Baerlocher MO, Lookstein RA, et al. Society of Interventional Radiology Position Statement on Catheter-Directed Therapy for Acute Pulmonary Embolism. 2018;29(3):293.

12. Fuller TJ, Paprzycki CM, Zubair MH, Hussain LR, Kuhn BA, Recht MH, et al. Initial experiences with endovascular management of submassive pulmonary embolism: is it safe? 2017;38:158-63.

13. Seyedhosseini J, Fadavi A, Vahidi E, Saeedi M, Momeni M. Impact of point-of-care ultrasound on disposition time of patients presenting with lower extremity deep vein thrombosis, done by emergency physicians. Turkish journal of emergency medicine 2018;18(1):20-4.

14. Bramante RM, Raio CCJTJoem. Near-miss in focused lower-extremity ultrasound for deep venous thrombosis. 2013;45(2):236-9.

15. Blaivas MJCcm. Ultrasound in the detection of venous thromboembolism. 2007;35(5):S224-S34. 
16. Goldstein LN, Wu M-TJAJoEM. A one year audit of patients with venous thromboembolism presenting to a tertiary hospital in Johannesburg, South Africa. 2018;8(1):12-5.

17. Rubin JM, Xie H, Kim K, Weitzel WF, Emelianov SY, Aglyamov SR, et al. Sonographic elasticity imaging of acute and chronic deep venous thrombosis in humans. 2006;25(9):1179-86.

18. Zhao L, Prior SJ, Kampmann M, Sorkin JD, Caldwell K, Braganza M, et al. Measurement of thrombus resolution using three-dimensional ultrasound assessment of deep vein thrombosis volume. 2014;2(2):140-7.

19. Angelson ME, Wooster DL, Wooster EMJJfVU. Pattern analysis of lower extremity venous thrombosis: implications for point of care ultrasound (POCUS) protocols. 2017;41(4):169-72.

20. De Maeseneer M, Bochanen N, van Rooijen G, Neglén PJEJoV, Surgery E. Analysis of 1,338 patients with acute lower limb Deep Venous Thrombosis (DVT) supports the inadequacy of the term "Proximal DVT". 2016;51(3):415-20.

\section{Images:}

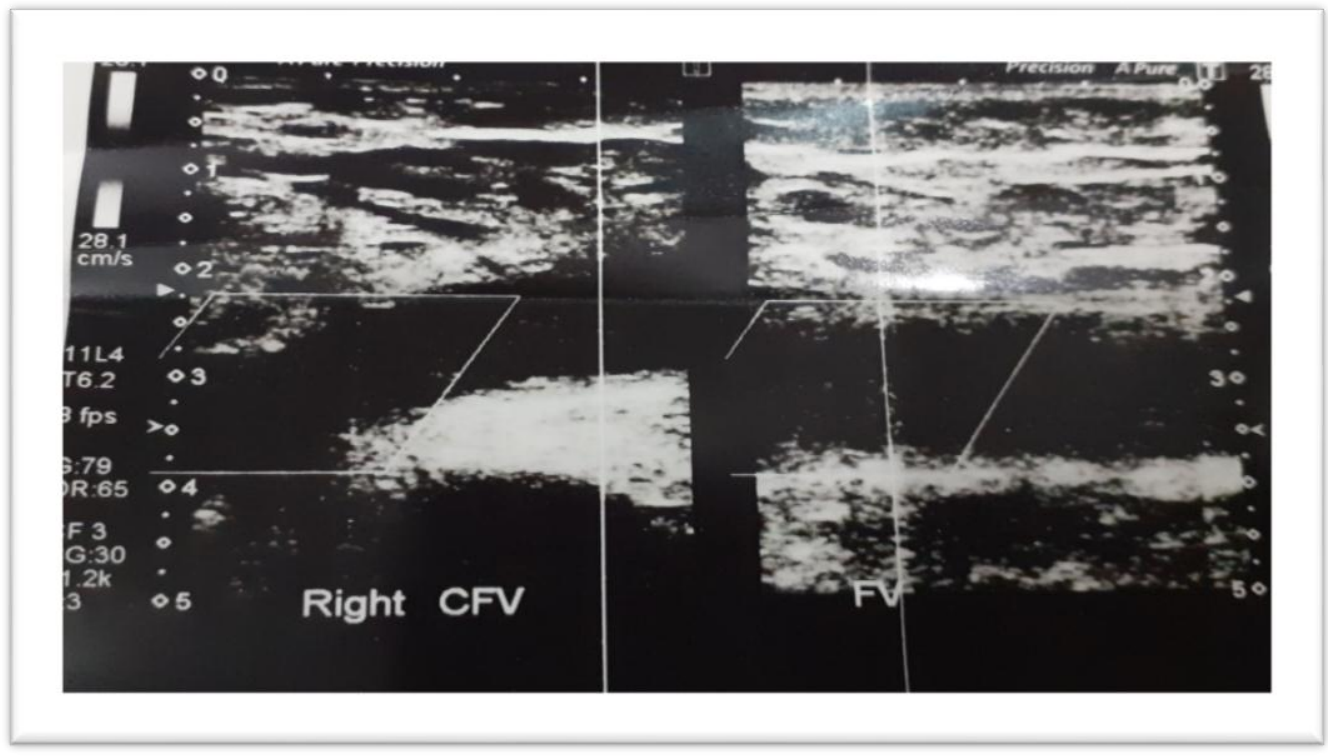

Image: 1 Right common femoral vein shows long segmental thrombus. 
American Journal of Health, Medicine and Nursing Practice ISSN 2520-4017 (Online)

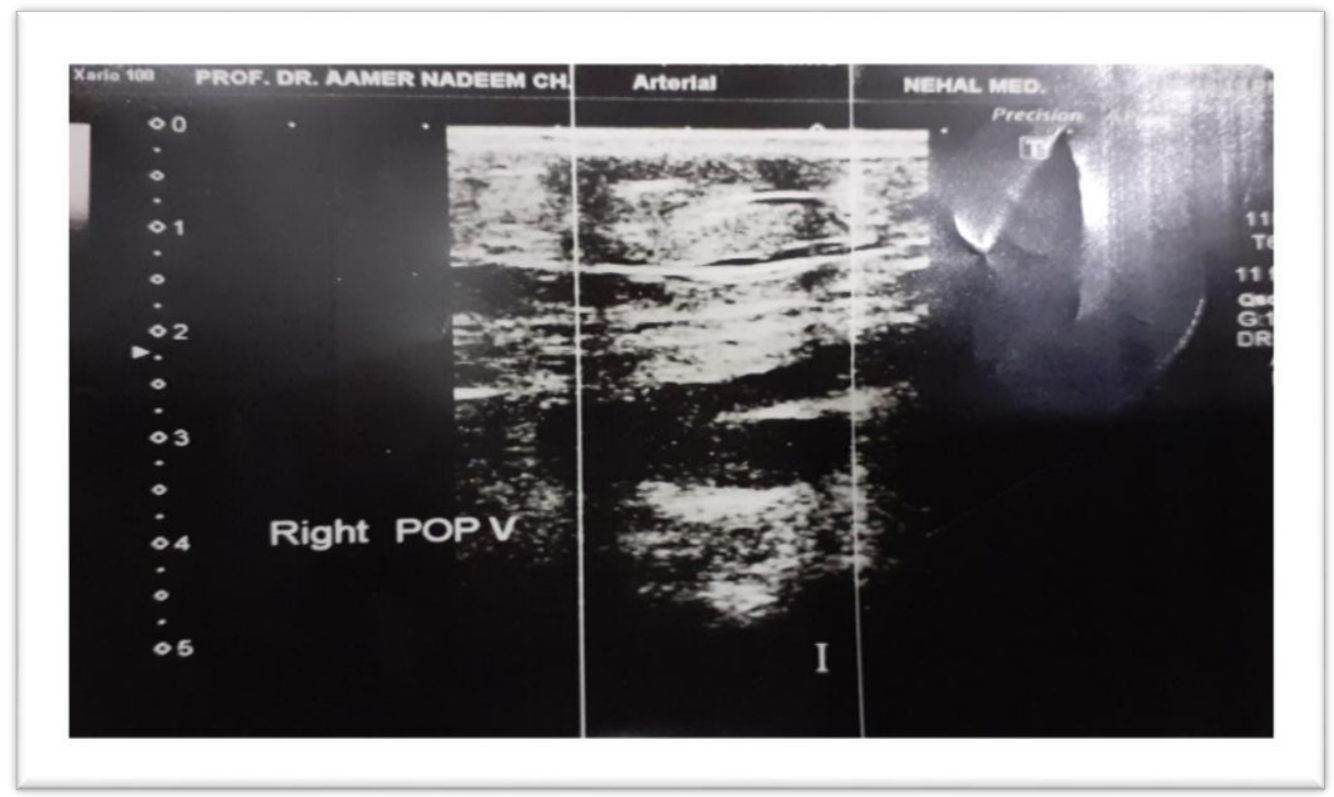

Image: 2 Thrombus is seen in popliteal vein shows acute DVT. 